2020-04-15

\title{
Antimony in paints and enamels of everyday items
}

\section{Turner, Andrew}

http://hdl.handle.net/10026.1/15417

10.1016/j.scitotenv.2020.136588

Science of the Total Environment

Elsevier

All content in PEARL is protected by copyright law. Author manuscripts are made available in accordance with publisher policies. Please cite only the published version using the details provided on the item record or document. In the absence of an open licence (e.g. Creative Commons), permissions for further reuse of content should be sought from the publisher or author. 
2 Andrew Turner ${ }^{1 *}$, Montserrat Filella ${ }^{2}$

3

$4 \quad{ }^{1}$ School of Geography, Earth and Environmental Sciences, University of Plymouth, Drake

5 Circus, Plymouth PL4 8AA, UK

$6{ }^{2}$ Department F.-A. Forel, University of Geneva, Boulevard Carl-Vogt 66, CH-1205 Geneva,

$7 \quad$ Switzerland

$8 \quad$ *aturner@plymouth.ac.uk

9

10 Accepted $6^{\text {th }}$ January 2020

11 https://doi.org/10.1016/j.scitotenv.2020.136588 


\section{Abstract}

Concentrations of antimony have been determined for paints and enamels that are available to the consumer or accessible to the public by x-ray fluorescence spectrometry. The metalloid was only present in consumer paints of a speciality (e.g. artistic) nature, but was common in old household paints as an anti-chalking agent and in brightly-coloured contemporary exterior paints (on roads, street furniture and playground equipment, for example) as a colour fastener with concentrations ranging from a few hundred to about $25,000 \mu \mathrm{g} \mathrm{g}^{-1}$. Antimony was also found in contemporary container glass and ceramic products as an additive or opacifier and as

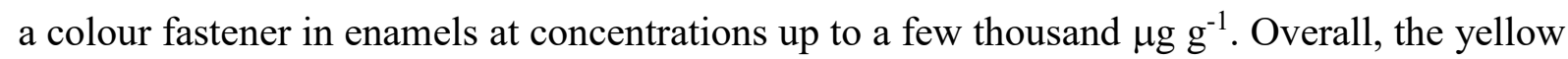
pigment, lead antimonite, was only evident in two ceramic products, with $\mathrm{Sb}$ concentrations exceeding $62,800 \mu \mathrm{g} \mathrm{g}^{-1}$. Available data in the literature suggests that, while $\mathrm{Sb}$ concentrations up to $30 \mu \mathrm{g} \mathrm{g}^{-1}$ are bioaccessible in exterior paints and that concentrations of up to $20 \mathrm{mg} \mathrm{L}^{-1}$ are migratable in some ceramicware, no relevant regulations are currently in place. Given our lack of understanding of the health impacts of $\mathrm{Sb}$, more studies on its toxicity and mobility from commonly encountered products are required.

Keywords: antimony; paints; enamels; ceramics; glass; XRF 


\section{Introduction}

Antimony ( $\mathrm{Sb}$ ) has been used as a pigment, and mainly as antimony sulphide and lead antimonite, for several thousand years (Aldersey-Williams, 2011; Schwarz-Schampera, 2014). Currently, $\mathrm{Sb}$ has the status of a technologically-critical element that is essential for economic development, and although the principal present uses are in antimonial lead, as a flame retardant synergist in textiles and plastics and as a catalyst (e.g. in the production of polyethylene terephthalate, PET), the element is still used in pigments, ceramic glaze and glass (Orisakwe, 2012; Dupont et al., 2016). The most recent European data available indicate that Sb employed as an additive in glass manufacture represents $1 \%(250 \mathrm{t})$ of total use while application in pigments, paints and ceramics constitutes about 4.5\% (1100 t); these values compare with 3.9\% in PET production and $32.9 \%$ in flame retardant synergist manufacture (European Communities, 2008). In addition to these applications, Sb readily and widely contaminants many contemporary consumer plastics at low levels through the recycling of electronic and PET-based products (Turner and Filella, 2017).

While the behaviour of $\mathrm{Sb}$ in different environmental compartments is relatively well-known, or at least has been extensively studied (Filella et al., 2009), the toxicological implications of its pervasiveness in everyday products are far less understood. Specifically, the occurrence and fate of $\mathrm{Sb}$ as a catalyst or synergist have received recent attention (Haldimann et al., 2013; Snedeker, 2014; Turner and Filella, 2017), with concentrations migratable from the matrix regulated for (PET) food containers (European Commission, 2005) and children's toys (European Parliament and the Council of the European Union, 2009). However, its occurrence, function, mobility and potential impacts in contemporary paints, consumer glass and ceramicware are poorly documented, despite the obvious exposure routes arising from these applications. 
In this study, we examined the occurrence of $\mathrm{Sb}$ in the paints and enamels of various consumer goods and everyday items that have been purchased new or that are in circulation and in extant applications on structures which the public are exposed to and where the presence and/or mobility of other elements, like $\mathrm{Cd}, \mathrm{Cr}(\mathrm{VI})$ and $\mathrm{Pb}$, are highly regulated on environmental and health grounds (Sheets, 1999; Turner, 2019). Measurements of Sb were made in situ or in the laboratory by energy dispersive $\mathrm{x}$-ray fluorescence (XRF) spectrometry and relevant information in the literature on its migration from any applications was reviewed. The investigation complements an earlier study that determined the occurrence and distribution of $\mathrm{Sb}$ as catalytic residue or a flame retardant synergist in consumer plastics using the same protocols and techniques (Turner and Filella, 2017).

\section{Materials and methods}

About 400 measurements of $\mathrm{Sb}$ have been performed on distinct regions (in terms of colour or texture) of 335 samples acquired from or located within south west England. Many of the samples had been measured as part of independent research projects (Turner et al., 2015; Turner et al., 2016; Turner and Solman, 2016; Turner, 2019a) and here published and unpublished data on Sb have been compiled, while other samples were analysed specifically for the purposes of the present study. The painted and enameled samples are described and categorised below.

(1) "Interior extant paint" on interior walls, doors, frames, skirting boards and floors of various private households in the city of Plymouth ranging in age from 50 to 100 years;

(2) "Exterior extant paint" on the exteriors of these and other private households and including walls, guttering and timber;

(3) "Municipal extant paint" on external wooden, tarmacked and metallic structures and street furniture accessible to the public in the city of Plymouth, including roads, post boxes, phone boxes, benches, gates and playground equipment; 
(4) "Extant boat paint" applied to the hull, decking and cabin of pleasure craft or small commercial vessels located on the coastal foreshores in the vicinity of Plymouth and that were either abandoned or in use;

(5) "Consumer paint" for internal and external decoration or for artwork and that had been purchased within the past five years;

(6) "Painted toys/equipment": the paint on wooden and metallic toys and other consumer items (e.g. tools, storage tins, artefacts) around the household;

(7) "Consumer bottle enamel": the decorated enamels on glass for the containment and sale of wine, beer and food products;

(8) "Drinking glass enamel"; the enamels on glassware for drinks and other food-contact items purchased new or secondhand;

(9) "Ceramicware enamel": the enameled decorations and glaze of (mainly food-contact) ceramicware in circulation and purchased new or secondhand or loaned from colleagues.

For each sample, the condition and principal colour (or colours) were noted, along with any distinguishing signage (e.g. place of manufacture). For intact extant paints, and to avoid disturbance or damage to the surface, $\mathrm{Sb}$ and other elements that included $\mathrm{Br}, \mathrm{Cl}, \mathrm{Ni}, \mathrm{Pb}, \mathrm{Ti}$ and Zn, were measured in situ and on each distinctive colour and, where possible, the undecorated substrate of structures using a battery-operated Niton XL3t 950 He GOLDD+ portable XRF spectrometer. Here, the 8 -mm diameter detector window of the instrument, containing the 200 $\mu \mathrm{A}-50 \mathrm{kV}$ x-ray source and large area drift detector, was pointed directly over the area to be measured with the aid of real-time video footage projected on to the touchscreen display through a charged-couple device camera. Counting was activated by the trigger mechanism of the XRF spectrometer for a period of between 30 and 60 seconds in a "plastics" mode, whose performance has been verified by independent measurements of acid digests by inductively 
coupled plasma spectrometry (Turner, 2019b). Successive measurements were made at $50 \mathrm{kV}$ $40 \mu \mathrm{A}$ and $20 \mathrm{kV}-100 \mu \mathrm{A}$ and employing a thickness correction of between 0.05 and $0.1 \mathrm{~mm}$. For flakes of paint carefully retrieved from structures, new paints purchased in hardware stores that had been applied by brush to a series of glass or cardboard slides and air-dried for 24 to 48 $\mathrm{h}$, and new and secondhand ceramic and glass products of less than $200 \mathrm{~mm}$ in length, the XRF was operated under the same conditions but in the laboratory while housed nose-upwards in an accessory stand and activated remotely via USB. To discriminate Sb present in any décor of these products from $\mathrm{Sb}$ in the glass or ceramic glaze, readings were also taken on undecorated regions of the substrate, where possible. For products greater than $200 \mathrm{~mm}$ in length the surface to be measured was cradled in a radiation apron on a stainless steel table and the XRF operated likewise but handheld.

Elemental concentrations (in $\mu \mathrm{g} \mathrm{g}^{-1}$ ) were derived from secondary (fluorescent) $\mathrm{x}$-ray spectral peaks using standardless fundamental parameters software. Polyethylene Niton reference discs impregnated with various elements (including $\mathrm{Sb}$ ) were analysed at regular intervals throughout each measurement session and returned concentrations that were within $15 \%$ of certified values. The limit of detection for $\mathrm{Sb}$, defined as three standard counting errors of background intensity (and derived from errors in samples that did not return a signal for $\mathrm{Sb}$ ) varied according to the precise matrix and thickness but was generally in the range 40 to $100 \mu \mathrm{g} \mathrm{g} \mathrm{g}^{-1}$. Precision, derived from quintuplicate measurements of the same location on a range of samples, was always better than $20 \%$.

\section{Results and discussion}

\subsection{Occurrence, sources and concentrations of Sb}


Table 1 shows the number of samples considered in each category and the number of cases in which $\mathrm{Sb}$ was detected by XRF spectrometry, along with summary statistics of $\mathrm{Sb}$ concentrations. Note that where $\mathrm{Sb}$ was detected at multiple locations of a sample (for example, on distinctly different colours), the average detectable concentration and principal colour have been recorded. Also shown in Table 1 for each category are the colours of the samples that returned the highest $\mathrm{Sb}$ concentrations and the most common colours that returned detectable $\mathrm{Sb}$, as well as the number of cases in which $\mathrm{Sb}$ was detected with $\mathrm{Pb}$ at a concentration above $100 \mu \mathrm{g} \mathrm{g} \mathrm{g}^{-1}$

Overall, $\mathrm{Sb}$ was detected in at least one region of about a third of all samples tested and detection frequency exceeded $30 \%$ for extant paints (with the exception of those on boats), the enamels on drinking glasses and ceramicware products. Detection frequency was lowest on painted toys and household equipment and the enamels of consumer bottles. Antimony was detected in all colours, and including the colourless or lightly coloured glass of some products, but most commonly occurred in articles coloured yellow, red (including pink) or shades of white. Significantly, $\mathrm{Pb}$ was present at concentrations above $100 \mu \mathrm{g} \mathrm{g}^{-1}$ in nearly $90 \%$ of samples where $\mathrm{Sb}$ was detected and across all sample categories and among all colours.

The highest concentrations of $\mathrm{Sb}$ (above 50,000 $\mu \mathrm{g} \mathrm{g}^{-1}$ ) were encountered with concentrations of $\mathrm{Pb}$ above $100,000 \mu \mathrm{g} \mathrm{g}^{-1}$ in two bright yellow ceramic items (a tea cup and plate, with the XRF spectra of the former illustrated in Figure 1a). These are the only clear cases in which the pigment, lead antimonite or Naples yellow (whose theoretical molecular formula is $\mathrm{Pb}_{2} \mathrm{Sb}_{2} \mathrm{O}_{7}$ ), appears to have been used, and where excess $\mathrm{Pb}$ can be attributed to its additional use in the glazing of these products. The pigment may have been used in some older interior and exterior paints (where $\mathrm{Sb}$ concentrations exceeded 20,000 $\mu \mathrm{g} \mathrm{g}^{-1}$ ) but here concentrations of $\mathrm{Pb}$ were lower than the required stoichiometry of the compound and results and any relationships with 
colour may have been confounded by the effects of multiple layers of different paint formulations measured in situ.

151

152

153

154

155

156

157

158

159

160

161

162

163

164

165

166

167

Regarding paints available to the contemporary consumer, Sb was present at concentrations of a few thousand $\mu \mathrm{g} \mathrm{g}^{-1}$ in two artists paints containing the bright red pigment, cadmium sulphoselenide (CI Pigment Red 108), and exemplified by the XRF spectrum in Figure 1b, and a speciality leaded paint coloured by lead chromate molybdate sulphate red (CI Pigment Red 104), but was not detected in any paints for internal or external decoration. This suggests that $\mathrm{Sb}$ detected in extant paints of private properties arises from its presence in older applications, and a co-association with $\mathrm{Pb}$ may simply reflect the historical use of leaded paints in the same era. Antimony trioxide (CI Pigment White 11) was added to anatase titanium dioxide (CI Pigment White 6) to reduce chalking of the primary pigment before inherently antichalking formulations were available (Abel, 2000) and this may explain the presence of $\mathrm{Sb}$ in white extant paints in association with high concentrations of Ti (see XRF spectrum in Figure 1c). Antimony trioxide is, however, unlikely to be present (additionally) as a flame suppression synergist because concentrations of $\mathrm{Cl}$ and $\mathrm{Br}$ (indicators of halogenated flame retardants) were always too low to provide any form of fire retardancy (typically a few percent w/w; National Materials Advisory Board, 1970).

In extant municipal paints and boat paints, $\mathrm{Sb}$ was usually present at concentrations ranging from 1000 to $10,000 \mu \mathrm{g} \mathrm{g}^{-1}$ in formulations that were brightly coloured, and in particular in reds and yellows. In most cases, the XRF spectrum suggested that the primary pigment for colour was lead chromate (CI Pigment Yellow 34), lead chromate molybdate sulphate or bismuth vanadate (CI Pigment Yellow 184) (Figure 1d). Clearly, Sb is not used in these cases for colour itself but appears to be used as a fastener where colour protection from UV radiation is required (USAC, 2017). 
Among the glass containers and drinking vessels, including newly-purchased articles, Sb was

present in the glass itself in three products, presumably as a fining component or decolourising agent (Grund et al., 2010), and appeared to be used as a colour fastener on the brightly coloured enamels of ten products, with maximum $\mathrm{Sb}$ concentrations in the glass and enamel of about $4000 \mu \mathrm{g} \mathrm{g}^{-1}$ and $8000 \mu \mathrm{g} \mathrm{g}^{-1}$, respectively. Multiple measurements of ceramicware in circulation suggested that $\mathrm{Sb}$ was present in the glaze and uncoloured enamels of 12 products and at concentrations ranging from about 1000 to $3000 \mu \mathrm{g} \mathrm{g}{ }^{-1}$, possibly as an opacifier in articles fired at low temperatures (Demont et al., 2012), and in the coloured enamels of 15 products. As above, $\mathrm{Sb}$ was present as a pigment (lead antimonite) in two cases but appeared to be more commonly encountered in significantly lower concentrations (1000 to $4500 \mu \mathrm{g} \mathrm{g}^{-1}$ ), presumably as a colour fastener for other pigments.

\subsection{Migration and potential environmental and health impacts of Sb}

Given concerns about the toxicity of Sb (IARC, 1989; NTP, 2018), the lack of regulations that directly apply (or that have been applied) to the sample types considered herein and the data presented in Table 1 is surprising. The most relevant regulation concerns material like paint, that can be scraped off children's toys, where a maximum migratable limit (mobilised by 0.07 $\mathrm{M} \mathrm{HCl}$ ) is $560 \mu \mathrm{g} \mathrm{g}^{-1}$ according to the amended EU Toy Safety Directive (European Parliament and the Council of the European Union, 2009). However, the results reported in Table 1 suggest that the type of paint used on children's toys and other household wooden and metallic artefacts rarely contains detectable $\mathrm{Sb}$. Whether this reflects attempts to avoid $\mathrm{Sb}$ in such products or simply results from no requirement for the metalloid in these applications is unclear. Perhaps of greater concern to human health in this perspective is the use of $\mathrm{Sb}$ as a fastener in brightly coloured paints used on public playground equipment. The highest concentration of Sb returned for such equipment was about $6000 \mu \mathrm{g} \mathrm{g}^{-1}$, with an earlier study revealing that up to $0.56 \%$ of $\mathrm{Sb}$ in these formulations was accessible to dilute $\mathrm{HCl}$ (Turner et al., 2016). This suggests about 
$30 \mu \mathrm{g} \mathrm{g}^{-1}$ of $\mathrm{Sb}$ in playground paint could be accessible to children through inadvertent ingestion. While this concentration is well below the limit stipulated by the Toy Safety Directive, it should be noted that, in the majority of cases considered here, $\mathrm{Sb}$ was co-associated with high concentrations of lead and that any synergistic effects of these elements on human health are unknown.

Much recent attention has focussed on the migration of $\mathrm{Sb}$ from single-use PET food-contact items like water bottles and ready meal trays. Regardless of storage conditions, measured concentrations of $\mathrm{Sb}$ in bottled water have not exceeded the European Commission limit for natural mineral water of $5 \mu \mathrm{g} \mathrm{L}^{-1}$ or the US Environmental Protection Agency maximum contaminant level of $6 \mu \mathrm{g} \mathrm{L}^{-1}$ (Shotyk et al., 2006; Greifenstein et al., 2013; Payan et al., 2017; Roje and Sutalo, 2019). While concentrations of Sb reported in food contained and cooked in PET packaging sometimes exceed the $40 \mu \mathrm{g} \mathrm{kg}^{-1}$ limit specified by European Union Regulation 10/2011, typical food consumption results in intakes of Sb that are significantly below the World Health Organization (WHO) tolerable daily intake (TDI) of $6 \mu \mathrm{g} \mathrm{kg}^{-1}$ (Haldimann et al., 2007; Whitt et al., 2016). Antimony concentrations in contemporary PET as residual catalyst (typically 200 to $300 \mu \mathrm{g} \mathrm{g}^{-1}$; Westerhoff et al., 2008) are, however, an order of magnitude lower than concentrations in many articles of ceramicware and glassware reported in the present study. Moreover, the latter are subject to sustained or long-term use and to foodstuffs that may be relatively acidic.

Despite the occurrence of $\mathrm{Sb}$ in historical and contemporary food-contact ware, the degree of its migration from such articles is poorly documented. Burns (1935) studied the migration of $\mathrm{Sb}$ compounds from the enamel (and glaze) of a ceramic jug that contained $9800 \mu \mathrm{g} \mathrm{g}^{-1} \mathrm{Sb}$ using various preparations of $0.5 \%$ citric acid solution. Antimony concentrations of up to 5.6 $\mathrm{mg} \mathrm{L}^{-1}$ were detected colorimetrically in successive 18-hour extracts of the original article in which the acid was introduced while boiling, but extraction rose to $20 \mathrm{mg} \mathrm{L}^{-1}$ when the jug had 
been scoured. Although the author was unable to definitively state that such concentrations were toxic, the prohibition of Sb in enamelware was called for. More recently, Demont et al. (2012) studied the mobilisation of $\mathrm{Sb}$ and other elements from customised ceramicware that had been treated with various pigments (including $\mathrm{Sb}_{2} \mathrm{O}_{3}$ as and opacifier, but of unspecified concentration) and glazed. Extraction after $24 \mathrm{~h}$ was greatest, and up to about $0.2 \mathrm{mg} \mathrm{L}^{-1}$, for $4 \%$ acetic acid but tests were not performed after disturbing the glaze to simulate sustained usage and washing. Given the high levels of $\mathrm{Sb}$ in some of the ceramicware and enamels studied herein and regulations limiting both the concentrations and migration of lead and cadmium from ceramicware and the lip area (within $2 \mathrm{~cm}$ of the rim) of decorated drinking glasses (Council of the European Communities, 1984; Rebeniak et al., 2014) it would seem prudent to investigate the rates and mechanisms of $\mathrm{Sb}$ migration from food-contact articles more systematically. The potential risks arising from migration should also be evaluated with respect to the WHO $6 \mu \mathrm{g} \mathrm{kg}^{-1}$ TDI for the metalloid.

Unlike Sb-containing electronic plastics and PET food packaging, and, with the exception of container glassware, the products and applications described herein are not generally recycled. Thus, the use of $\mathrm{Sb}$ in ceramics, enamels and paints requires its disposal through landfill or incineration, both of which are challenging because of regulatory or environmental constraints on the metalloid in the waste stream. For example, in Europe the limit value for Sb leaching from granular solid waste (by deionised water and according to standard batch test EN 12457) is among the lowest for all elements reported, and above $5 \mu \mathrm{g} \mathrm{Sb} \mathrm{g}^{-1}$ waste is classified as hazardous (Environment Agency, 2013). With regard to incineration, and despite the volatility of many antimony compounds, about $50 \%$ of the metalloid remains in bottom ashes due to interactions with other chemicals in the fuel bed and the consequent formation of thermally stable antimonates (Paoletti et al., 2001). Because of the leaching of Sb from incinerator bottom 
ashes, the EU considers the element to be the most problematic in terms of the reuse and recovery potential of waste material (European Communities, 2008).

\section{Conclusions}

Antimony has a variety of applications in paints, glass and ceramicware that are available to the consumer and accessible to the public. It is commonly encountered in old domestic paints as an anti-chalking agent but appears to be limited to contemporary consumer paints of a speciality nature where the metalloid is used as a fastener for brightly coloured, and often toxic, primary pigments. It is more likely to be found in contemporary paints applied to exterior municipal structures, like roads, boats, playground equipment and telephone kiosks, where it serves as a fastener to reduce the deterioration of bright colours. Antimony is present in glass and glazed ceramics and appears to be added as a fastener for pigments in enamels but clear evidence of its occurrence as the primary pigment, lead antimonite, was restricted to two bright yellow articles of ceramicware. Little information exists on the migration or accessibility of $\mathrm{Sb}$ in paints, glass and ceramicware but given concerns about its heath risks and that regulations exist for other metals in such products, more systematic research into Sb mobility is called for.

\section{Acknowledgements}

We are grateful to Alex Taylor, Kevin Solman and Andy Fisher, UoP, for technical support throughout the study. 


\section{References}

Abel, A.G., 2000. Pigments for paint. In: Lambourne, R., Strivens, T.A. (Eds.), Paint and Surface Coatings: Theory and Practice. Woodhead Publishing, Cambridge, UK, pp. 91165.

Aldersey-Williams, H., 2011. Periodic Tales. The Curious Lives of the Elements. Penguin Books, 2011.

Burns, R.H., 1935. Antimony compounds extracted from enamelware by citric acid solutions. Analyst 60, 220-222.

Council of the European Communities, 1984. Council Directive of 15 October 1984 on the approximation of the laws of the Member States relating to ceramic articles intended to come into contact with foodstuffs (84/500/EEC). Official Journal of the European Communities No L 277/12.

Demont, M., Boutakhrit, K., Fekete, V., Bolle, J., Van Loco, J., 2012. Migration of 18 trace elements from ceramic food contact material: Influence of pigment, $\mathrm{pH}$, nature of acid and temperature. Food and Chemical Toxicology 50, 734-743.

Dupont, D., Arnout, S., Jones, P.T., Binnemans, K., 2016. Antimony recovery from end-of-life products and industrial process residues: A critical review. Journal of Sustainable Metallurgy 2, 79-103.

Environment Agency 2013. Waste Sampling and Testing for Disposal to Landfill. EA, Bristol, 36pp.

European Commission, 2005. Commission Directive 2005/79/EC of 18 November 2005 amending Directive 2002/72/EC relating to plastic materials and articles intended to come into contact with food. Official Journal of the European Union L302, 35-45.

European Communities, 2008. European Union Risk Assessment Report. Diantimony trioxide. DRAFT. CAS No: 1309-64-4. EINECS No: 215-175-0. RISK ASSESSMENT Sweden.

European Parliament and the Council of the European Union, Directive 2009/48/EC of the European Parliament and of the Council of 18 June 2009 on the safety of toys, Official Journal of the European Union L170/1, 2009.

Filella, M., Williams, P.A., Belzile, N., 2009. Antimony in the environment: knowns and unknowns. Environmental Chemistry 6, 95-105.

Greifenstein, M., White, D.W., Stubner, A., Hout, J.,Whelton, A.J., 2013. Impact of temperature and storage duration on the chemical and odor quality of military packaged 
water in polyethylene terephthalate bottles. Science of Total Environment 456-457, 376383.

Grund, L., Jonson, B., Lundstedt, K., 2010. The influence of basicity on oxygen activity and antimony oxide fining efficiency in alkali alkaline earth aluminosilicate glasses. Glass Technology - European Journal of Glass Science and Technology Part A 50, 241-246.

Haldimann, M., Blanc, A., Dudler, V., 2007. Exposure to antimony from polyethylene terephthalate (PET) trays used in ready-to-eat meals. Food Additives and Contaminants 24, 860-868.

Haldimann, M., Alt, A., Blanc, A., Brunner, K., Sager, F., Dudler, V., 2013. Migration of antimony from PET trays into food simulant and food: determination of Arrhenius parameters and comparison of predicted and measured migration data. Food Additives and Contaminants A 30, 587-598.

IARC, 1989. Antimony trioxide and antimony trisulfide. In: Some Organic Solvents, Resin Monomers and Related Compounds, Pigments and Occupational Exposures in Paint Manufacture and Painting. IARC Monographs on the Evaluation of Carcinogenic Risks to Humans, Volume 47, 291-305.

NTP, 2018. Report on Carcinogens Monograph on Antimony Trioxide October, Office of the Report on Carcinogens, National Toxicology Program, National Institute of Environmental Health Sciences, National Institutes of Health, Research Triangle Park, US.

National Materials Advisory Board, 1970. Trend in Usage of Antimony. Report of the panel on antimony of the Committee on the Technical Aspects of Critical and Strategic Materials. Publication NMAB 274, National Academy of Sciences, Washington DC.

Orisakwe, O.E., 2012. Other heavy metals: antimony, cadmium, chromium and mercury. In: Toxicity of Building Materials, ed. F. Pacheco-Torgal, S. Jaladi and A. Fucic. Woodhead Publishing, Oxford, pp297-333.

Paoletti, F., Sirini., P, Seifert., H., Vehlow, J., 2001. Fate of antimony in municipal solid waste incineration. Chemosphere 42, 533-543.

Payan, L., Poyatos, M.T., Munoz, L., La Rubia, M.D., Pacheco, R., Ramos, N., 2017. Study of the influence of storage conditions on the quality and migration levels of antimony in polyethylene terephthalate-bottled water. Food Science and Technology International 23, $318-327$. 
Rebeniak, M., Wojciechowska-Mazurek, M., Mania, M., Szynal, T., Strzelecka, A., Starska, K., 2014. Exposure to lead and cadmium released from ceramics and glassware intended to come into contact with food. Roczniki Państwowego Zakładu Higieny 65, 301-309.

Roje, V., Sutalo, P., 2019. Trace and major elements in Croatian bottled waters. Journal of Geochemical Exploration 201, 79-87.

Schwarz-Schampera, U., 2014. Antimony. In: Critical Metals Handbook, ed. G.Gunn. Wiley, Chichester. pp 70-98.

Sheets, R.W., 1999. Acid extraction of lead and cadmium from newly-purchased ceramic and melamine dinnerware. Science of the Total Environment 234, 233-237.

Shotyk,W., Krachler,M., Chen, B., 2006. Contamination of Canadian and European bottled waters with antimony from PET containers. Journal of Environmental Monitoring 8, 288-292.

Snedeker, S.M., 2014. Antimony in food contact materials and household plastics: Uses, exposure, and health risk considerations. In: Toxicants in Food Packaging and Household Products, ed. S.M. Snedeker, Springer, London, pp 205-230.

Turner, A., 2019a. Heavy metals in the glass and enamels of consumer container bottles. Environmental Science and Technology 53, 8398-8404.

Turner, A., 2019b. Trace elements in laundry dryer lint: A proxy for household contamination and discharges to waste water. Science of the Total Environment 665, 568-573.

Turner, A., Filella, M., 2017. Field-portable-XRF reveals the ubiquity of antimony in plastic consumer products. Science of the Total Environment 584-585, 982-989.

Turner, A., Solman, K.R., 2016. Lead in exterior paints from the urban and suburban environs of Plymouth, south west England. Science of the Total Environment 547, 132-136.

Turner, A., Comber, S., Rees, A.B., Gkiokas, D., Solman, K., 2015. Metals in boat paint fragments from slipways, repair facilities and abandoned vessels: An evaluation using field portable XRF. Talanta 131, 372-378.

Turner, A., Kearl, E.R., Solman, K.R., 2016. Lead and other toxic metals in playground paints from South West England. Science of the Total Environment 544, 460-466.

USAC, 2017. United States Antimony Corporation: Uses and Formulations. http://usantimony.com/uses formulations.htm accessed 9/2019.

Westerhoff, P., Prapaipong, P., Shock, E., Hillaireau, A., 2008. Antimony leaching from polyethylene terephthalate (PET) plastic used for bottled drinking water. Water Research $42,551-556$. 
364 Whitt, M., Brown, W., Danes, J.E., Vorst, K.L., 2016. Migration of heavy metals from recycled polyethylene terephthalate during storage and microwave heating. Journal of Plastic Film and Sheeting 32, 189-207.

367 
Table 1: Occurrence, distribution and concentrations of Sb in paints, ceramicware and container glass. Categories are shown with the number of samples analysed, $n$ (column 2) is the number of cases in which $\mathrm{Sb}$ was detected, mean, median, minimum and maximum concentrations are in $\mu \mathrm{g} \mathrm{g}^{-1}$, colour $\mathrm{rax}_{\mathrm{max}}$ is the colour of the article returning the highest $\mathrm{Sb}$ concentration, colour $\mathrm{com}_{\mathrm{com}}$ is the colour where $\mathrm{Sb}$ was most commonly detected, and $\mathrm{Sb}-\mathrm{Pb}$ denotes the number of cases in which $\mathrm{Sb}$ co-existed with $\mathrm{Pb}$ above a concentration of $100 \mu \mathrm{g} \mathrm{g}^{-1}$.

\begin{tabular}{|c|c|c|c|c|c|c|c|c|}
\hline & $n$ & mean & median & $\min$ & $\max$ & colour $_{\max }$ & colour $_{\text {com }}$ & $\mathrm{Sb}-\mathrm{Pb}$ \\
\hline Interior extant paint ( $n=25$ ) & 10 & 8670 & 7630 & 2610 & 24500 & yellow & white $(n=6)$ & 10 \\
\hline Exterior extant paint $(n=25)$ & 9 & 2530 & 1020 & 260 & 8540 & brown & white $(n=3)$ & 9 \\
\hline Municipal extant paint ( $n=93$ ) & 38 & 2220 & 1190 & 147 & 27500 & grey & yellow $(n=18)$ & 32 \\
\hline Extant boat paint $(n=21)$ & 6 & 3000 & 993 & 176 & 8080 & red & $\operatorname{red}(n=3)$ & 4 \\
\hline Consumer paints ( $n=18$ ) & 3 & 2070 & 2670 & 520 & 3020 & red & $\operatorname{red}(n=3)$ & 3 \\
\hline Painted toys/equipment ( $n=33$ ) & 2 & 318 & 318 & 215 & 420 & red & $\operatorname{red}(n=2)$ & 1 \\
\hline Consumer bottle enamel $(n=20)$ & 3 & 1290 & 1610 & 629 & 1640 & green & various $(n=1)$ & 2 \\
\hline Drinking glass enamel $(n=31)$ & 10 & 2310 & 1510 & 507 & 7790 & yellow & green $(n=2)$ & 8 \\
\hline Ceramicware enamel ( $n=69)$ & 23 & 6430 & 933 & 308 & 62800 & yellow & yellow $(n=6)$ & 22 \\
\hline Total $(n=335)$ & 104 & 3360 & 1180 & 147 & 62800 & yellow & yellow $(n=29)$ & 91 \\
\hline
\end{tabular}


Figure 1: XRF spectra of four samples and shown as counts per second versus energy from 0 to 35 $\mathrm{keV}$. (a) A second hand teacup pigmented with lead antimonate and glazed with lead oxide and tin oxide; (b) an artists' paint pigmented with cadmium sulphoselenide and where $\mathrm{Sb}$ is present, presumably, as a fastener; (c) the exterior paint of a private household where $\mathrm{Sb}$ is likely present as an anti-chalking agent with titanium dioxide and lead; (d) a galvanised steel playground gate coloured by bismuth vanadate and where $\mathrm{Sb}$ is present as a colour fastener.
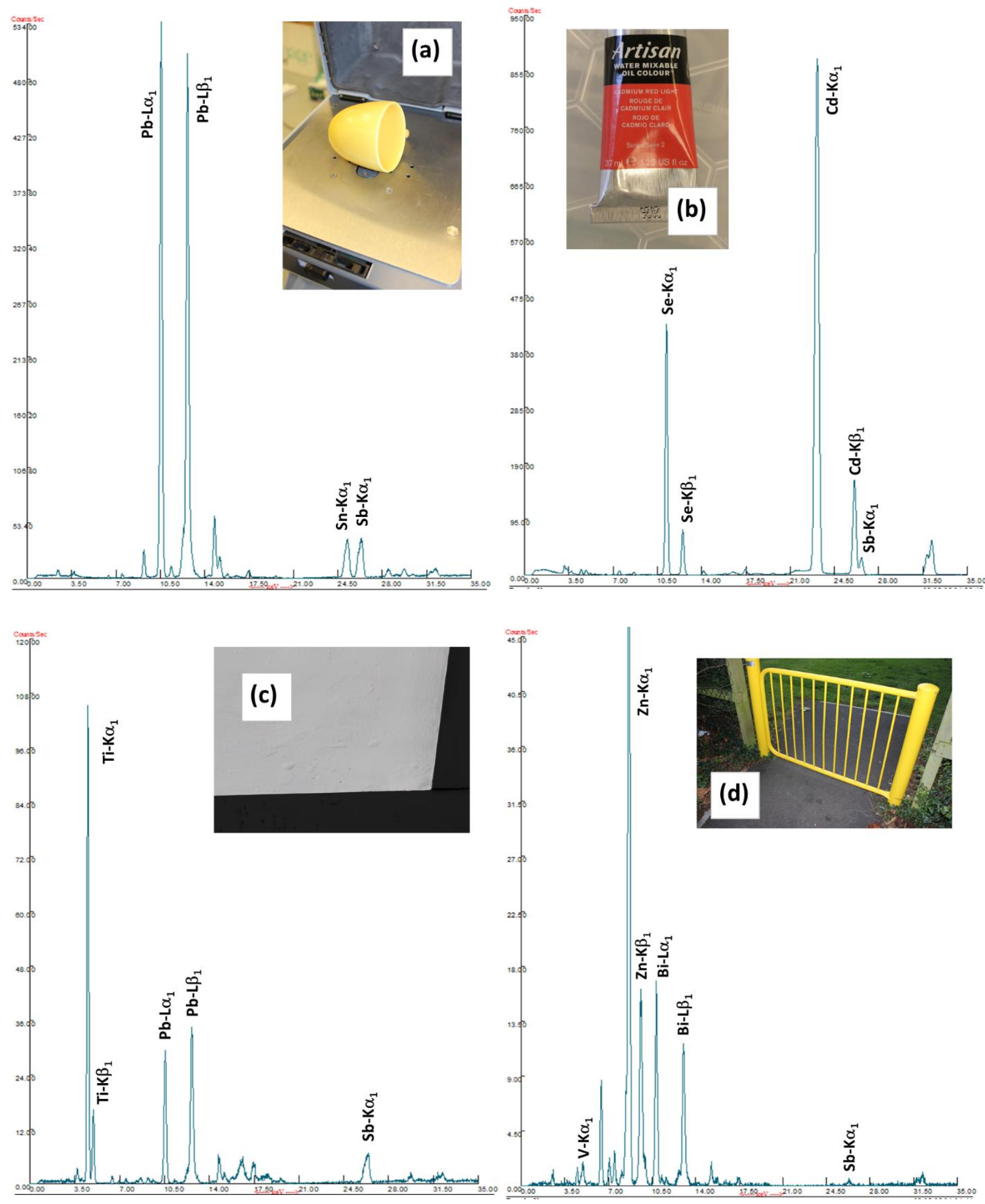